ation of hypoxemic hearts. J Mol Cell Cardiol 1980;12: 797-808.

2. Corno A, Samaja M. The reoxygenation phenomenon [Letter]. J Thorac Cardiovasc Surg 1993;105:373.

3. Samaja M, Motterlini R, Santoro F, Dell'Antonio G, Corno A. Oxidative injury in reoxygenated and reperfused hearts. Free Radic Biol Med 1994;16:255-62.
4. Samaja M, Casalini S, Allibardi S, Corno A. Effects of energy demand in ischemic and hypoxemic isolated rat hearts. Adv Exp Med Biol 1994 (In press).

5. Del Nido P, Mickle DAG, Wilson GJ, et al. Inadequate myocardial protection with cold cardioplegic arrest during repair of tetralogy of Fallot. J THORAC CARDIOVASC SURG 1988;95:223-9.

\title{
IMPACT OF NITRIC OXIDE INHALATION ON RIGHT VENTRICULAR FAILURE AFTER IMPLANTATION OF NOVACOR LEFT VENTRICULAR ASSIST SYSTEM
}

Paul Michel Mertes, MD, Georges Pinelli, MD, Thierry Hubert, MD, Jean Pierre Carteaux, MD, Etienne Hottier, MD, Alain Larcan, MD, and Jean Pierre Villemot, MD, Nancy, France

The left ventricular assist system (LVAS) (Baxter Healthcare Corporation, Novacor Division, Oakland, Calif.) used as a bridge in the expectation of transplantation has been shown to effectively improve cardiac output even in patients with biventricular failure. ${ }^{1}$ Nevertheless, many patients still require some sort of inotropic support and/or pulmonary vasodilator therapy to optimize right ventricular $(R V)$ performance. Consequently, appropriate selection of potential recipients calls for careful evaluation of preimplantation pulmonary artery pressure and vascular resistance, which should remain in a suitable range to ensure successful heart transplantation. However, in certain cases, high pulmonary resistance necessitating concomitant RV support has been observed. We report here one such case in which an early rise in pulmonary artery pressure led to rapid RV failure, and the use of inhaled nitric oxide allowed us to forgo the need for mechanical RV support.

A 54-year-old man with dilated idiopathic cardiomyopathy received an LVAS because of repeated episodes of left ventricular failure necessitating increasing doses of sympathomimetic drugs. This patient was regarded eligible for heart transplantation. The preoperative pulmonary vascular resistance was 4 Wood units. After he was weaned from cardiopulmonary bypass (CPB), a rapid rise in mean pulmonary arterial pressure was observed from 40 to $65 \mathrm{~mm} \mathrm{Hg}$, associated with a decrease in RV ejection fraction from $17 \%$ to $6 \%$ and persistent low pump output below $3 \mathrm{~L} / \mathrm{min}$. This reduced pump output was related to difficulties in pump filling as witnessed by the reduction in LVAS peak filling volume, which precisely monitors this phenomenon. This change occurred despite the use of isoproterenol $(0.1 \mu \mathrm{g} / \mathrm{kg}$ per minute $)$ and epinephrine $(0.2$ $\mu \mathrm{g} / \mathrm{kg}$ per minute) therapy, concomitant with administra-

From the Laboratoire d'Explorations Métaboliques et Endocriniennes and the Service de Chirurgie Cardiaque et Transplantations Cardiothoraciques, Centre Hospitalier Universitaire de Brabois, Nancy, France.

J Thorac Cardiovasc Surg 1995;109:1251

Copyright (C) 1995 by Mosby-Year Book, Inc.

$0022-5223 / 95 \$ 3.00+0 \quad \mathbf{1 2 / 8 / 6 1 6 9 2}$ tion of prostacyclin at an increasing rate of 5 to $20 \mathrm{ng} / \mathrm{kg}$ per minute. After an hour, in the absence of a satisfactory hemodynamic response, CPB was reinstituted. Nitric oxide was then administered as a specific pulmonary vasodilator therapy in a premixed concentration of $900 \mathrm{ppm}$ nitric oxide in nitrogen (CFPO, Paris, France). Nitric oxide was introduced into the breathing system circuit near the endotracheal tube via a separate flowmeter. The nitric oxide flow rate was adjusted to reach a concentration of $50 \mathrm{ppm}$. Almost 30 minutes later, a progressive increase in peak LVAS filling volume was noted. CPB was then progressively interrupted. At the same time, LVAS pump output rapidly increased to $5 \mathrm{~L} / \mathrm{min}, \mathrm{RV}$ function improved (ejection fraction 17\%), and mean pulmonary arterial pressure dropped to $35 \mathrm{~mm} \mathrm{Hg}$. The day after, mean pulmonary arterial pressure further decreased to $27 \mathrm{~mm} \mathrm{Hg}$ while RV ejection fraction rose to $23 \%$. Inotropic support and nitric oxide inhalation were then progressively decreased and the patient was extubated after 5 days.

This observation underscores the possibility afforded by nitric oxide inhalation in the reduction of acutely increased pulmonary vascular resistance after CPB during LVAS implantation. ${ }^{2,3}$ In our opinion, its feasibility should be considered before any decision is made to institute RV support in cases of early inadequate LVAS system filling.

\section{REFERENCES}

1. McCarthy PM, Portner PM, Gareth Tobler H, Starnes VA, Ramasamy N, Oyer PE. Clinical experience with the Novacor ventricular assist system: bridge to transplantation and the transition to permanent application. J Thorac Cardiovasc Surg 1991;102:578-87.

2. Rich GF, Murphy GD, Roos CM, Johns RA. Inhaled nitric oxide: selective pulmonary vasodilatation in cardiac surgical patients. Anesthesiology 1993;78:1028-35.

3. Schrantz D, Huth R, Wippermann CF, Ritzefeld S, Schmitt FX, Oerlet H. Nitric oxide and prostacyclin lower suprasystemic pulmonary hypertension after cardiopulmonary bypass. Eur J Pediatr 1993;152:793-6. 